\title{
Neural Systems Involved In Moral Judgment and Moral Action
}

\author{
Geert-Jan Will ${ }^{1,2}$ and Eduard T. Klapwijk $k^{2,3}$ \\ ${ }^{1}$ Institute of Psychology, Leiden University, 2333 AK Leiden, The Netherlands, ${ }^{2}$ Leiden Institute for Brain and Cognition (LIBC), Leiden University Medical Center, \\ 2300 RC Leiden, The Netherlands, and ${ }^{3}$ Department of Child and Adolescent Psychiatry, Curium —Leiden University Medical Center, 2300 AA Leiden, The Netherlands \\ Review of Yoder and Decety
}

For centuries, philosophers have debated whether moral judgments are the product of active deliberation or that intuition drives our decisions about right and wrong. During the last decade and a half, cognitive neuroscientists have stepped into this debate by scanning people's brains while they make judgments about scenes or scenarios involving harm and fairness. This endeavor has proven fruitful in showing that neural systems underlying automatic, intuitive, and emotional processes and controlled, deliberative, and cognitive processes are involved in making moral judgments. Although neuroscience has increased our understanding of the neural mechanisms common to people's moral judgments, not much is known about how activation in these networks might differ between people depending on how strongly they react to injustice or their capacity to understand and share other people's emotions (i.e., empathy). In a recent paper in The Journal of Neuroscience, Yoder and Decety (2014) report on a set of findings showing that individual differences in justice sensitivity, but not empathy, predict moral judgments and the associated activation in

Received May 15, 2014; revised June 15, 2014; accepted June 26, 2014. We thank Donal Cahill, Alek Chakroff, Eveline Crone, and Berna Güroğlu for their comments on an earlier draft of this manuscript.

Correspondence should be addressed to Geert-Jan Will, Institute of Psychology, Leiden University, Wassenaarseweg 52, 2333 AK, Leiden, The Netherlands. E-mail: g.j.will@fsw.leidenuniv.nl.

DOI:10.1523/JNEUROSCI.2005-14.2014

Copyright $\odot 2014$ the authors $\quad 0270-6474 / 14 / 3410459-03 \$ 15.00 / 0$ neural circuitry involved in moral cognition. We discuss their findings and propose that although empathic feelings might not be necessary for moral judgments, they might play a role in motivating moral action.

Yoder and Decety (2014) scanned 40 healthy adults using functional magnetic resonance imaging (fMRI) while these participants watched scenes in which people harmed or helped others. Participants also filled out questionnaires that assessed empathy and justice sensitivity, either when they were victims of unfairness themselves (self-oriented justice sensitivity) or when they saw that someone else was treated unfairly (other-oriented justice sensitivity). Behavioral results showed that participants who reported high levels of self- and other-oriented justice sensitivity rated harmful actors as more blameworthy than participants who reported low levels of justice sensitivity. Participants with high levels of self-oriented justice sensitivity were also more likely to praise helpful actors. Furthermore, when evaluating harmful compared with helpful acts, participants with high levels of other-oriented justice sensitivity showed enhanced activation in brain regions implicated in reasoning about other people's mental states (i.e., mentalizing), including the right temporoparietal junction (TPJ) and the dorsomedial prefrontal cortex (PFC). High levels of justice sensitivity were also related to a greater coupling of the TPJ and the right dorsolateral PFC-a region implicated in cognitive controlduring helping scenarios relative to harm scenarios. No associations were found between self-reported empathy and brain activity during moral evaluations.

Increased activity in neural circuitry involved in higher-order cognitive functions in people who report greater sensitivity to injustice might indicate that justice sensitivity in the context of this moral evaluation task is associated with (social) cognitive aspects of moral judgments rather than with processing emotional aspects of a moral scenario. These findings are in line with results from a recent meta-analysis (Bzdok et al., 2012). In this study, data from 247 experiments and 1790 participants were pooled to investigate neural activation associated with moral cognition that overlaps with, and that is distinct from, activation associated with inferring other people's thoughts, beliefs, or desires in "mentalizing" tasks or activation associated with vicariously experiencing other people's emotions in empathy tasks. Common to moral cognition, theory of mind and empathy was activation in the "mentalizing network" (TPJ, medial PFC, and precuneus), suggesting that people infer other people's mental states during moral decisions and when they feel empathy for someone else (Bzdok et al., 2012). Crucially, recruitment of the dorsal anterior cingulate cortex (dACC) and the anterior insula was consistently found in empathy tasks but not in moral cognition tasks. The dACC 
and insula are involved in encoding representations of the physiological state of the body and the representation of one's own and other's emotional states (Rilling and Sanfey, 2011). However, empathy is not solely the product of activation in the $\mathrm{dACC}$ and insula, and as such the absence of activation in these regions in moral judgment studies does not strongly argue against the involvement of empathy in moral judgment. Nonetheless, behavioral evidence indicates that moral evaluations are to a greater degree influenced by the aversion to harming others than by the amount of empathy felt for a victim suffering (Miller et al., 2014).

Together, these findings, spanning a range of studies using multiple methods, suggest that empathy may not be necessary for judging moral actions as right or wrong. Nonetheless, empathic feelings still might play a crucial role in acting in moral situations. Possibly, self-reported empathy did not correlate with neural activation during the perception of moral harm and assistance in the Yoder and Decety (2014) study because the task did not require moral action. This notion is supported by a study showing that the mentalizing network is activated when people witness another person being excluded, but that only those individuals who additionally engage the ACC and insula subsequently comfort the victim of exclusion (Masten et al., 2011). Similarly, people who recruit the insula to a greater extent when they see someone in pain are more likely to help this person (Hein et al., 2010). This suggests that although sharing emotions with a victim of harm might not be necessary for judging the harmful act to be wrong, empathy might be a motivator for moral action.

Future research could investigate how neural responses involved in moral evaluations relate to subsequent moral action involving costs and benefits for self and others. For example, observers of injustice are willing to give up a share of their resources to retaliate against perpetrators even in the absence of immediate benefit to themselves. This form of costly thirdparty punishment is crucial to the evolution and maintenance of large-scale cooperation. That is, cooperation between anonymous individuals breaks down rather quickly when free-riding cannot be punished by a third-party and the effects of a punishment threat on cooperation are much stronger when sanctions are costly to administer (Balliet et al., 2011). Interestingly, the neural networks implicated in such social decisions roughly overlap with the neural networks typically found in studies of moral cognition (Rilling and Sanfey, 2011). Using stimuli like Yoder and Decety's (2014), it could be tested whether people are willing to punish the actors when they have to give up a share of their own resources and how such decisions are motivated by empathic feelings. For example, moral transgressions with a higher emotional content are judged to deserve more punishment (Krueger et al., 2014), but the neural correlates of witnessing such transgressions and how they relate to costly punishment have yet to be discovered. Similarly, activation in neural systems involved in empathic sadness might motivate people to give up some of their own rewards to compensate a victim of an offense. Future research could also investigate the neural correlates of rewarding morally praiseworthy actions, which has been shown to be as crucial for maintaining large-scale cooperation as punishment (Balliet et al., 2011). The fact that Yoder and Decety (2014) not only investigated morally bad actions (i.e., harm) but also instances of helping behavior provides a foundation for such work.

After a decade and a half during which neuroscience has increased our understanding of the contributions of neural systems involved in emotion and cognition to judgments of right and wrong, it is time to further investigate how activation in these systems can influence why some people decide to act on a moral judgment and others do not. Combining moral cognition paradigms with economic games might offer a valuable approach for future research. A good example for such an endeavor is provided by studies that examined the role of the ventromedial prefrontal cortex (vmPFC) in moral judgment and economic decision-making. Patients with vmPFC lesions are more likely to endorse killing one person to save multiple others in moral dilemmas involving high levels of conflict. This finding has been suggested to reflect a more rational strategy in moral decisions, possibly due to less sensitivity to an aversive emotional signal associated with harming the one person (Koenigs et al., 2007). At the same time, patients with vmPFC lesions seem to act less rationally than control subjects in an economic game by more often turning down a sum of money to prevent receiving less than another person (Koenigs and Tranel, 2007). Neuroeconomics shed further light on this apparent discrepancy by showing that vmPFC activity during decisions to donate money to charity correlates with the subjective value of such donations and overlaps with activation associated with subjective value computation of basic rewards, such as food. These results suggest that the vmPFC plays a role in integrating affective and cognitive information into subjective value signals that guide behavior (Hare et al., 2010). Researchers interested in moral cognition then built upon this idea and showed that the vmPFC seems to be similarly involved in integrating affective signals generated in the amygdala with a more cognitive assessment of outcomes of a moral action to form an "all things considered" moral judgment (Shenhav and Greene, 2014).

These findings on the role of the vmPFC in moral judgment and social behavior illustrate the value of combining paradigms used in moral cognition and tools from behavioral economics. Such a multidisciplinary approach can inform our understanding of: (1) specific contributions of emotion and cognition to moral judgment and behavior, (2) the computations involved in social judgments and decisions, (3) the neural structures that underlie these computations, and (4) which subcomponents of moral judgments contribute to subsequent moral actions. Moreover, as Yoder and Decety (2014) show, each of the preceding notions might differ as a function of individual dispositions, such as justice sensitivity. Future research could combine insights from both fields to investigate how individual differences in justice sensitivity influence moral actions of altruism or punishment and how neural activation during moral evaluations predicts moral actions. Ultimately, an increased understanding of the proximate mechanisms that motivate people to act on their moral judgments might give us more insight into how we can effectively encourage moral action in response to injustice.

\section{References}

Balliet D, Mulder LB, Van Lange PA (2011) Reward, punishment, and cooperation: a meta-analysis. Psychol Bull 137:594-615. CrossRef Medline

Bzdok D, Schilbach L, Vogeley K, Schneider K, Laird AR, Langner R, Eickhoff SB (2012) Parsing the neural correlates of moral cognition: ALE meta-analysis on morality, theory of mind, and empathy. Brain Struct Funct 217: 783-796. CrossRef Medline

Hare TA, Camerer CF, Knoepfle DT, Rangel A (2010) Value computations in ventral medial prefrontal cortex during charitable decision making incorporate input from regions involved in social cognition. J Neurosci 30:583590. CrossRef Medline

Hein G, Silani G, Preuschoff K, Batson CD, Singer $\mathrm{T}$ (2010) Neural responses to ingroup and outgroup members' suffering predict individ- 
ual differences in costly helping. Neuron 68 : 149-160. CrossRef Medline

Koenigs M, Tranel D (2007) Irrational economic decision-making after ventromedial prefrontal damage: evidence from the Ultimatum Game. J Neurosci 27:951-956. CrossRef Medline

Koenigs M, Young L, Adolphs R, Tranel D, Cushman F, Hauser M, Damasio A (2007) Damage to the prefrontal cortex increases utilitarian moral judgements. Nature 446:908-911. CrossRef Medline

Krueger F, Hoffman M, Walter H, Grafman J (2014) An fMRI investigation of the effects of belief in free will on third-party punishment. Soc Cogn Affect Neurosci

Masten CL, Morelli SA, Eisenberger NI (2011) An fMRI investigation of empathy for 'social pain' and subsequent prosocial behavior. Neuroimage 55:381-388. CrossRef Medline

Miller RM, Hannikainen IA, Cushman FA (2014) Bad actions or bad outcomes? Differentiating affective contributions to the moral condemnation of harm. Emotion 14:573-587. CrossRef Medline

Rilling JK, Sanfey AG (2011) The neuroscience of social decision-making. Annu Rev Psychol 62:23-48. CrossRef Medline

Shenhav A, Greene JD (2014) Integrative moral judgment: dissociating the roles of the amygdala and ventromedial prefrontal cortex. J Neurosci 34:4741-4749. CrossRef Medline Yoder KJ, Decety J (2014) The good, the bad, and the just: justice sensitivity predicts neural response during moral evaluation of actions performed by others. J Neurosci 34:41614166. CrossRef Medline 